\title{
Challenging norms of crisis communication and preparedness by listening to voices from the (dis)ability movement in Sweden
}

\author{
Magnus Eriksson \\ RISE, Research Institutes of Sweden
}

Jörgen Lundälv

Department of Social Work, Gothenburg University, Sweden

Department of Surgical and Perioperative Science, Umeå University, Sweden

Elisabet M. Nilsson

School of Arts and Communication (K3), Malmö University, Sweden

\begin{abstract}
This paper presents the result of a survey study where representing members of the disability movement in Sweden have shared their experiences of living and acting during the first year of the Covid-19-pandemic. The aim was to identify crisis communication challenges and where additional communication material and methods are needed for supporting people in going from knowledge to taking action for achieving a higher level of crisis preparedness. The paper also includes a brief summary of a literature review of previous international research on disabilities and the Covid-19 pandemic. Three categories of crisis communication challenges were identified displaying a vulnerability in society and pointing towards several important knowledge gaps that ought to be addressed in order to achieve crisis preparedness among all people. The results indicate that there is a need for additional communication materials and methods that can be appropriated to individual needs, and dialogue methods between authorities and people in order to counteract normative assumptions in crisis communication aimed at different target groups.
\end{abstract}

Keywords - crisis communication, crisis preparedness, disabilities, norm-creative

SUGGESTED CITATION: Eriksson, M., Lundälv, J., \& Nilsson, E. M. (2021). Challenging norms of crisis preparedness by listening to voices from the (dis)ability movement in Sweden. Proceedings of the International Crisis and Risk Communication Conference, Volume 4 (pp. 19-22). Orlando Fl: Nicholson School of Communication and Media. https://doi.org/10.30658/icrcc.2021.05

\section{INTRODUCTION}

Norm-creative crisis preparedness is a research project aiming to explore and design communication strategies and methods for supporting crisis preparedness and responses before and during times of crisis. The focus is on marginalized groups and disabilities not included in the normative assumptions of general crisis communication. This paper presents the result of a survey study where representing members of the disability movement in Sweden have shared their experiences of living and acting in a pandemic. The aim of the study was to identify crisis communication challenges during the Covid19-pandemic (and other crises) and where additional communication material and methods are needed for supporting people, and in particular people with disabilities, in going from knowledge to taking action for achieving a higher level of crisis preparedness.

Previous studies [7], put forward that there are communities in society that are more difficult to reach out to during crises, such as people with disabilities who are dependent on special support in the event of a crisis situation. To achieve crisis preparedness, it is important that all people in a society are included and involved and that crisis communication is designed in such a way that everyone can interpret it and understand how to adapt the recommendations to their life situations. To get an overview of the state of the art of crisis communication and research specifically targeting disabled people, a literature review of previous international research on disabilities and the Covid-19 pandemic was carried out. 


\section{LITERATURE REVIEW}

The literature review shows that research focusing on crisis communication and crisis preparedness among people with various kinds of disabilities is rather sparse. In the following a brief summary of the literature review of research on disabilities and the Covid-19 pandemic is presented. A full presentation of the literature review including all references can be found in Report 1: Norm-creative crisis preparedness [7].

\begin{tabular}{|l|l|}
\hline Research on the Covid-19 pandemic in relation to: & References: \\
\hline $\begin{array}{l}\text { People with intellectual disabilities, research from different } \\
\text { perspectives and subject disciplines. }\end{array}$ & $\begin{array}{l}\text { Embregts, Tournier \& Frielink (2020), Ervin, D. A., } \\
\text { \& Hobson-Garcia, D. (2020), Mills et al. (2020), } \\
\text { Tromans et al. (2020), Tummers et al. (2020), } \\
\text { Zaagsma et al. (2020), Festen et al. (2021) }\end{array}$ \\
\hline $\begin{array}{l}\text { Children and young people of different ages with different } \\
\text { disabilities and their situations. }\end{array}$ & $\begin{array}{l}\text { [3], Fegert et al. (2020), Ghosh et al. (2020), Jones } \\
\text { (2020), Whitney \& Whitney (2020), Battistin et al. } \\
\text { Riddell (2021) }\end{array}$ \\
\hline $\begin{array}{l}\text { Mental illness and the need for psychosocial support measures } \\
\text { for people with various disabilities. }\end{array}$ & $\begin{array}{l}\text { [4], Fegert, J. M. et al. (2020); Florence et al. (2020), } \\
\text { Velden, van der et al. (2020), Porat et al. (2020), }\end{array}$ \\
\hline Communication that draws attention to disability perspectives. & {$[10]$} \\
\hline $\begin{array}{l}\text { People with various physical disabilities, such as mobility } \\
\text { impairments. }\end{array}$ & {$[6]$} \\
\hline People with neuropsychiatric disabilities. & {$[8]$} \\
\hline People with hearing impairments. & {$[9]$} \\
\hline People with visual impairments. & {$[1]$} \\
\hline
\end{tabular}

Table. 1 A brief summary of the literature review of international research on disabilities and the Covid-19 pandemic.

To sum up, the Covid-19 pandemic has highlighted the vulnerability of people with disabilities during crises and that their crisis preparedness needs to be strengthened. The literature review indicates that disability organizations in Sweden but also in our neighbouring countries have had strong driving forces to investigate the consequences of the pandemic for different target groups based on different areas of life. It is also interesting to note that the disability organizations have had contact with each other and shared experiences with their member organizations. Another interesting observation is that disability organizations have had contact with and in some cases collaborated with authorities by, for example, arranging exchanges of knowledge. This has happened through the arrangement of seminars and webinars in the middle of the ongoing pandemic [7]. Similarly, the European Disability Forum has monitored both the disability perspective and human rights (disability law perspectives) based on the impact of the pandemic for people with various disabilities.

\section{METHODS}

A web survey was applied for collecting data. The survey consisted of 17 questions and was sent in November 2020 to representatives of disability organizations and patient organizations. 62 responses were collected. The responses were analysed through a SWOT (Strengths, Weaknesses, Opportunities, and Threats) analysis [7] by three coders. The analysis resulted in a series of identified communication challenges that in the second step were categorised and summarised in three main communication challenges. When analysing the results, a long range of other types of challenges also surfaced but were not selected to be part of the main collection of challenges since they fell out of the scope of this project. These challenges were though carefully documented and shared with our stakeholders for them to address and act upon in other settings beyond this project.

\section{RESULTS OF THE SURVEY STUDY}

Three categories of crisis communication challenges when communicating with people with disabilities during the Covid19-pandemic were identified:

I) Lack of understanding and knowledge of needs, conditions and what it means to build crisis preparedness for people with disabilities

Both members of the disability and patient organizations (people with disabilities) and their assistants largely lack targeted communication materials and methods for increasing the understanding of what it means to be prepared and how 
individuals can take a greater responsibility for communicating their needs before and during a crisis. Many organizations and their members have not developed any crisis plans that meet the individual variation in needs and conditions among disabled people. Also, authorities, municipalities and companies largely lack knowledge about how to meet the needs of disabled people or how they have been affected during crises. As also pointed out in the literature review, knowledge in society is generally low about the situation of people with disabilities, which becomes even clearer during a crisis. There is thus an urge for dialogue methods for improving the communication between all parties.

II) Lack of and/or inability to develop digital competencies

Many of the members of the disability and patient organizations have a low level of digital competency, and no access to digital media platforms and/or video conferencing systems. About half of the members use e-mail. The study does not reveal whether it is a generational or disability issue, but the problem points at being greater among elderly. The members who are unable to access the information directly become dependent on second-hand sources from people who may themselves have difficulties in grasping the crisis information due to various reasons (language skills, education, lack of support from their employers etc). The situation causes "political poverty" since they are cut off from the democratic conversation by not being able to participate in digital meetings, online education, the public debate etc.

III) Lack of social crisis preparedness

Many members of the disability and patient organizations have suffered from loneliness and isolation during the Covid19 pandemic, which lead to an increased vulnerability and that they become less independent. Due to the risk of infection, many physical meetings, education and youth activities have been suspended. We need a better understanding of how (safe) isolation breaking measures can be taken in order to counteract loneliness. Communication materials and methods are needed for supporting people in building a better crisis preparedness by also addressing the social aspects.

\section{DISCUSSION}

The result of the study displays a vulnerability in society and points at several important knowledge gaps that ought to be addressed in order to achieve a higher level of crisis preparedness among all people. Methods for promoting dialogue between authorities and people about their needs and rights are needed, but also for highlighting individuals' own responsibilities, capabilities and shortcomings in the event of a crisis. Besides channelling crisis information top-down, crisis communication material and methods should thus also support and create guidance and initiatives for individuals to achieve better crisis preparedness on their own. This can be done by starting from their life situations, conditions and needs and based on that develop individually tailored crisis plans. However, current national crisis communication does not primarily offer such a bottom-up perspective. Instead, the crisis communication risks ending up in building on rather normative assumptions of what constitutes crisis preparedness among people, no matter what their life situations and conditions for taking action look like. As also pointed out in the study, there is great individual variation in needs and conditions among people with disabilities, which makes it difficult to start from general crisis plans. Thus, there is a call for developing communication materials and methods that can be adapted to individual needs, and for developing dialogue methods between authorities and people in order to counteract normative assumptions in crisis communication aimed at different target groups, such as people with various kinds of disabilities.

\section{CONCLUSION}

The conclusions drawn from this study are based on both theoretical knowledge and practical knowledge by inviting different stakeholders to describe and reflect upon their experiences during the Covid-19 pandemic. As indicated by the project title, we assume a norm-creative approach which stands for a desire to counteract norms by using creativity and action-based approaches. In our case this will be done through design research, and more specifically by setting up a design process where we, in collaboration with the target groups, explore and design solutions targeting the identified communication challenges.

As pointed out, there is a need for dialogue methods to gain an understanding of how different target groups want to be communicated with and which messages that create relevance. By creating conditions for such dialogues and by listening to voices from the disability movement can we go beyond a normative view of what constitutes crisis communication and preparedness and explore what we can learn from (dis)abled people whose everyday lives have always been characterized by extraordinary circumstances.

\section{Author Biography}

Magnus Eriksson. Senior Researcher, RISE Research Institutes of Sweden. E-mail: magnus.eriksson@ri.se 
Jörgen Lundälv. Associate Professor in Social Work, Department of Social Work, University of Gothenburg, Associate Professor in Traffic Medicine, Department of Surgical and Perioperative Science, Umeå university, E-mail: jorgen.Lundalv@socwork.gu.se

Elisabet M. Nilsson. Assistant professor in Interaction design, School of Arts and Communication (K3), Malmö University, Sweden. E-mail: elisabet.nilsson@mau.se

We thank everyone who has contributed to the study. The research is co-funded by Vinnova, Sweden's innovation agency. For more information about the project Norm-creative crisis preparedness, see: https://www.ri.se/en/what-we-do/projects/norm-creativecrisis-preparedness

\section{REFERENCES}

[1] Battistin, T., Mercuriali, E., Zanardo, V., Gregori, D., Lorenzoni, G., Nasato, L., \& Reffo, M. E. (2021). Distance support and online intervention to blind and visually impaired children during the pandemic Covid-19. Research in Developmental Disabilities, 108, 1-8. https://doi.org/10.1016/j.ridd.2020.103816

[2] Courtenay, K., \& Perera, B. (2020). Covid-19 and people with intellectual disability: impacts of a pandemic. Irish Journal of Psychological Medicine, 37(3):231-236._https://doi.org/10.1017/ipm.2020.45

[3] Eapen, V., Hiscock, H., \& Williams, K. (2020). Adaptive innovations to provide services to children with developmental disabilities during the Covid-19 pandemic. Journal of Paediatrics Child Health, 57(1), 9-11. https://doi.org/10.1111/jpc.15224

[4] Ghosh, R., Dubey, M. J., Chatterjee, S., \& Dubey, S. (2020). Impact of Covid-19 on children: special focus on the psychosocial aspect. Minerva Pediatrica, 72(3), 226-235. https://doi.org/10.23736/S0026-4946.20.05887-9

[5] Landes, S C., Turk, M A., Formica, M. K., McDonald, K E., \& Stevens, D. (2020). Covid-19 outcomes among people with intellectual and developmental disability living in residential group homes in New York State. Disability and Health Journal, 13, 1-5. https://doi.org/10.1016/j.dhjo.2020.100969

[6] Lebrasseur, A., Fortin-Bédard, N., Lettre, J., Bussiéres, E-L., Best, K., Boucher, N., Hotton, M., Beaulieu-Bonneau, S., Mercier, C., Lamontagne, M-E., \& Routhier, F. (2021). Impact of Covid-19 on people with physical disabilities: A rapid review. Disability and Health Journal, 14, 1-9. https://doi.org/10.1016/j.dhjo.2020.101014

[7] Lundälv, J., Nilsson, E. M., \& Eriksson, M. (2021). Rapport 1: Normkreativ krisberedskap: Ett forskningsprojekt med syftet att utveckla metoder som stärker allmänhetens beredskap inför och hantering av samhällskriser såsom pandemier [Report 1: Norm-creative crisis preparedness] (RISE rapport 2021:33). Retrieved on 2021-03-15 at http://umu.diva-portal.org/smash/record.jsf?pid=diva2\%3A1541055\&dswid=728

[8] Manning, J., Billian, J., Matson, J., Allen, C., \& Soares, N. (2020). Perceptions of families of individuals with autism spectrum disorder during the Covid-19 Crisis. Journal of Autism and Developmental Disorders, 1-9. https://doi.org/10.1007/s10803-020-04760-5

[9] Naylor, G., Burke, L. A., \& Holman, J. A. (2020). Covid-19 lockdown affects hearing disability and handicap in diverse ways: a rapid online survey study. Ear and Hearing, 41(6), 1442-1449. https://doi.org/10.1097/aud.0000000000000948

[10] Zaagsma, M., Volkers, K. M., Swart, E. A. K., Schippers, A. P., \& Van Hove, G. (2020). The use of online support by people with intellectual disabilities living independently during Covid-19. Brief Report. Journal of Intellectual Disability Research, 64(10), 750-756. https://doi.org/10.1111/jir.12770 